Editorial

\title{
Returns to Human Capital and the Incorporation of Highly-Skilled Workers in the Public and Private Sector of Major Immigrant Societies: An Introduction
}

\author{
Neli Demireva ${ }^{1, *}$ and Ivana Fellini ${ }^{2}$ \\ ${ }^{1}$ Department of Sociology, University of Essex, Colchester, CO4 3SQ, UK; E-mail: nvdem@essex.uk \\ 2 Department of Sociology and Social Research, University of Milano-Bicocca, 20126 Milano, Italy; \\ E-Mail: ivana.fellini@unimib.it \\ * Corresponding author
}

Submitted: 25 June 2018 | Published: 30 July 2018

\begin{abstract}
Across the major immigrant societies of the European Union, EU-15 countries, migrants and minorities still experience economic disadvantage. This failure of economic integration poses significant questions about the utilization of human capital, the management of mobility and the competitiveness of European labour markets (Cameron, 2011; OECD, 2017). Using a variety of datasets, this special issue pushes the debate forward in several ways. We will consider the integration outcomes of both migrants and second generation minority members in comparison to majority members. Labour market outcomes will be considered broadly: the probability of employment but also overqualification will be taken into account. Offering both analysis of single country cases and a cross-national comparison, the special issue will build a comprehensive picture of the factors associated with labour market disadvantage of migrant men and women, and their descendants-particularly, differential returns to foreign qualifications and educational credentials, differences between public and private sectors placements, and where possible the period of the economic crisis will be examined as well.
\end{abstract}

\section{Keywords}

ethnic minorities; ethnic penalty; highly-skilled work; immigrant societies; returns to human capital

\section{Issue}

This editorial is part of the issue "The Race for Highly-Skilled Workers", edited by Neli Demireva (University of Essex, UK) and Ivana Fellini (University of Milano Bicocca, Italy).

(C) 2018 by the authors; licensee Cogitatio (Lisbon, Portugal). This article is licensed under a Creative Commons Attribution 4.0 International License (CC BY).

\section{Introduction: The Debate on Migrants and Minorities' Returns to Human Capital in Major Immigrant Societies}

Across the major immigrant societies of Europe, migrants and minorities still experience significant economic disadvantage. This failure of economic integration poses important questions about the utilization of human capital, the management of mobility and the competitiveness of European labour markets. As the race for highly-skilled workers between the industrial economies of Europe, US, Canada and Australia intensifies, the success with which different regimes address the migration challenge and ensure the successful labour market incorporation of migrant workers becomes an issue of significant research and policy concern. The recognition of human capital is a major part of the story, and the collection of articles for this thematic issue suggests a relevant framework for the analysis of human capital returns in relation to employment outcomes and occupational attainment. Moreover, the articles consider the opportunities and labour market patterns of both new comers and their descendants as further shaped by their insertion into the public and the private sectors of the receiving societies.

Relying on both single-country and comparative studies, this thematic issue pushes forward in several ways 
the debate on minorities' returns to human capital in Europe (comparatively in a cross-national perspective, but also through case studies in the UK, Italy, France, the Netherlands and Spain) and the US. First, all contributions place important focus on how time and generational status affect immigrants and minorities' labour market outcomes and returns to human capital. Among migrants, recent arrivals can be expected to experience some disadvantage as they lack specific human capital, knowledge of the labour market and social networks upon which to rely when searching for work. The collected studies provide important understanding of progress over time and generations. While some contributions look at the role of education in shaping the integration outcomes of migrants and second-generation minority members in comparison to majority members, others analyse how migration status and educational attainment-and their interaction-affect immigrants' labour market position and occupational mobility over time. In addition, some contributions have also considered changes occurring during the economic crisis, comparing the pre- and post-crisis period.

Second, in order to understand the role played by migrants' and minorities' educational attainment on their economic incorporation, the articles in this thematic issue consider a broad range of labour market outcomes. Returns to education are a traditional area of study for economists in migration studies, and the most considered outcome has been wages and the minoritiesmajority wage gap (Chiswick, 1978, 2000). The choice of multiple outcomes on which to assess the returns to education such as activity, employment probability and occupational status, including over and under qualification (the term qualification here used interchangeably with education), allows the authors in this thematic issue to account both for the "quantitative" dimension of the economic incorporation of immigrantsparticipation and employment opportunities-and the "qualitative" dimension which considers the types of job immigrants and ethnic minorities find and their consistency with individual's educational attainment. The measures of overeducation adopted in the studies throughout this issue focus both on deviations from the mean qualification level in each occupation (such as in the Spanish case), the mean, median and mode (as in the Norwegian case), or on the individual perception of overqualification (as in the French case).

Where possible and relevant, the articles collected here further share a focus on the role of the public sector in labour market integration and on the skill rewards of migrants and minorities in this sector compared to private sector employment (see the case study of the UK, the Netherlands, Norway and the US). Research shows that well-educated minority individuals may seek public sector jobs in order to avoid discrimination (Heath \& Yu, 2005). Moreover, it has been demonstrated that graduates of female-dominated fields are disproportionately employed in the public sector (Roksa, 2005). States are often seen as having an obligation to serve as a model employer (Andrews, 2012), and minority members may note the better representation of penalized groups among the highly-skilled public sector employees observed in some countries (Chatterji, Mumford, \& Smith, 2011).

\section{Methodological and Empirical Frame}

One of the major analytical strengths of this thematic issue is that it relies on a wide array of national and international data, in order to make the most of the specific information included in national surveys (for the country case studies), international surveys (European Labour Force Survey for the cross-national comparison) or administrative data (Norway). Not every article in the thematic issue considers all the above-mentioned labour market outcomes due to the characteristics of the data they use, and the empirical strategy adopted. Thus, even though all articles deal with similar research questions, and adopt a similar multivariate approach, every contribution has its own peculiar specificity due to the characteristics of available data, which necessitates a modification of the empirical strategy in order to allow for the specificity of the migration phenomenon in national labour markets (with due attention paid to the integration debate in the national contexts).

It is important to highlight that the country studies cover both "old" migration countries as the US, UK, the Netherlands, Norway and France and "new" migration countries like Italy and Spain. This distinction encompasses a number of relevant factors with important implications for labour market insertion, such as the composition of the population, the share of foreign-born and second generation in each country, the difference of migrant motivations (the share of refugees is high in Nordic countries), as well as a whole set of observable (socio-demographic features) and unobservable (motivation, projects, etc.) characteristics. While the average educational attainment of immigrants across OECD countries is similar to the educational attainment of majority members in the receiving society, there are large differences across OECD countries (OECD, 2014): in Southern European countries, for example, the foreign-born have a lower educational profile than the foreign-born in Continental and Anglo-Saxon countries.

These differences motivate some of the empirical choices made in the contributions here collected. All contributions take into account the different areas of origin of migrants and minorities, paying due attention to the country case migration history. Yet, we have tried to adopt a common framework which allows for a distinction between the old EU (EU15), post-2004 EU (new EU) member states, as well as an identification of the generally more disadvantaged migrants from predominantly Muslim (North African and Middle Eastern) countries.

To facilitate the interpretation of the results we also adopt a common terminology. We distinguish between 
first generation immigrants (also called foreign born) and the second generation (individuals of immigrant descent born and raised in the receiving society). ${ }^{1}$ We compare their outcomes to those of majority members (constituting the majority group in the receiving society). The terms host and receiving society are used interchangeably. Where it is not possible to distinguish the second generation from majority members because there is no information on parents' country of origin in the data, the authors have clearly indicated this.

\section{The Country Studies: An Overview}

Using an extensive number of national and international datasets, the articles in this thematic issue delve into the patterns of labour market incorporation of migrants and minorities in Europe and the US. Despite the very different educational and occupational attainment of immigrants across countries, the country studies here collected depict a generalised and substantial under-utilization of their human capital. Indeed, all studies estimate lower returns to education for immigrants and minorities, in comparison with majority members with the same characteristics. Nevertheless, the penalization of the highlyeducated immigrants shows relevant differences across countries and the origin of the immigrants continues to be a most decisive factor, although the sector in which they are incorporated, public or private, and the period of observation, before or after the crisis matters too.

Zwysen and Demireva, in their contribution on the UK using Understanding Society, show that migrants face substantial difficulties in realizing good returns to their skills and human capital even if they have good degrees (Zwysen \& Demireva, 2018). Foreign-obtained higher degrees make very little difference for men but bring a small gain among women. Importantly, this discounting of qualifications seems to mainly occur among migrants whose productivity and skills may be less clear to employers to start with-more recent migrants, those with poorer language skills, and those without UK qualifications. They show improvement over generations, with most UK-born ethnic minorities doing relatively better than their migrant co-ethnics, with important exceptions such as Pakistani and Bangladeshi as well as male black African second-generation individuals who remain at high risk of unemployment and over-qualification. Importantly, working in the public sector in the UK seems to bring with it some protection from the risk of overqualification for the second-generation individuals and especially first-generation migrants.

Fellini, Guetto and Reyneri study the Italian case focusing on the returns to origin country education on the first job they find at arrival and on their subsequent occupational mobility (Fellini, Guetto, \& Reyneri, 2018). Building on an extensive national survey and focusing exclusively on the first generation, they find very poor re- turns to origin-country post-secondary education, with very few differences in the area of origin, apart for immigrants from Western countries. This suggests a strong labour market segmentation in the Italian case, and, importantly, in the context of the Italian labour market, differences in the transferability and quality of skills are scarcely relevant. The analysis shows that in such a peculiar labour market and migration system the modes of labour market insertion-e.g., formal search methods or relying on contacts with majority members-have a sizeable impact on skill returns. Similarly, post-secondary degrees are associated with low returns on subsequent mobility, although highly educated immigrants from new EU member states experience higher chances of upward mobility. As regards mobility, the recognition of educational credentials is decisive for the very few non-Western immigrants who succeed in improving their occupational attainment over time.

Fernández-Reino, Radl and Ramos focus on Spain and the impact of the economic crisis. This study builds on the two ad-hoc modules of the European Union Labour Force Survey (2008 and 2014) and on the national Labour Force Survey. The analysis shows that, before the crisis, differences among the majority group, immigrants and their descendants as regards labour market participation and employment chances are not significant, whereas quite sizeable penalization of immigrants is to be noted as regards "employment quality" measured by involuntary part time and overeducation (FernándezReino, Radl, \& Ramos, 2018). Nevertheless, labour market outcomes improve in the second generation. With the crisis, the penalization of immigrants dramatically increases as immigrant men are hit harder by the Great Recession than Spanish men in terms of employment (penalization that is perhaps underestimated given the fact that many immigrants have potentially returned to the country of origin).

The article by Guetto provides a comparative picture of returns to tertiary education for the foreign-born and the country-born population before and after the crisis (Guetto, 2018). Building on EU-LFS data from 2005 to 2013 for a selection of 10 Western European countries, this article shows that while employment gaps between immigrant and those born in the receiving society employment gaps remained unchanged in Northern and Continental Europe or even decreased, in Southern Europe, the immigrant disadvantage increased substantially, especially among men. No convergence between the selected European countries is observed regarding immigrant men's employment returns to tertiary education. While these returns increased in Southern European countries since the onset of the crisis, they still remained. Specifically, in countries such as Italy and Greece, the absolute returns to tertiary education for immigrants remain half of those of immigrants in Continental Europe, even after the economic crisis.

\footnotetext{
${ }^{1}$ Very few data allow such as Understanding Society in the UK, for the distinction of third generation individuals of immigrant descent. In this case second and third generation individuals have been grouped together.
} 
Larsen, Rogne and Birkelund show that counter to their initial hypotheses, relative differences in overqualification do not seem to differ substantially by gender, nor by sector refuting the idea that the public sector plays a sheltering role (Larsen, Rogne, \& Birkelund, 2018). They find that, while the prevalence of overqualification is generally higher for immigrants than for their descendants and majority members, these differences seem to diminish by time since immigration. For second and further generations, the prevalence of overqualification is generally comparable to its level among majority members. Thus, while overall overqualification is higher among the highly educated, the relative differences between immigrants and majority members remain substantial.

In France, Brinbaum's research shows that ethnic penalties in employment and in access to skilled occupations are observed for all immigrants but they decline in the second generation for almost all groups apart from immigrants of North-African and Sub-Saharan African origin (Brinbaum, 2018). Lack of human capital explains to some extent migrants' labour market disadvantages, particularly French knowledge and educational qualification transferability are very important. These variables have however a greater impact on occupation and perceived overqualification than on employment. In addition, tertiary degrees acquired abroad are largely discounted.

Using data from the first wave of the Netherlands Longitudinal Life-Course Study (NELLS), Khoudja demonstrates disadvantages in employment probabilities for men and women from different foreign origin groups compared to the Dutch majority even after accounting for differences in human capital (Khoudja, 2018). These remain stark for Turkish and Moroccan men but are less pronounced among women. Having a foreign degree brings substantial disadvantage. Overeducation appears less pronounced in the public sector than in the private sector with little differences among minorities and majority members in their returns to human capital in the Dutch public sector.

Finally, Lo lacono and Demireva examine the US and find some sheltering for migrants and minorities in the public sector. Occupational attainment gains remain associated with public sector employment, underlying its importance in the fight against inequality and the existence of racial and ethnic hierarchies. Tertiary degrees especially the ones obtained in the US have a very important role in the labour market of the private sector, even more so among first- and second-generation women than among men. Yet, certain groups remain at a disadvantage considering they have been born in the US-such as Black men and second-generation Asian women (Lo lacono \& Demireva, 2018).

Some further interesting patterns can be noted. The articles in this thematic issue demonstrate low transferability of degrees obtained in educational systems other than the one of the receiving society, even in the case of tertiary degrees, which pattern in line with previous research appears to prevent access to highly-skilled occupations (Lancee \& Bol, 2017). It is hard however to explain the penalization of the second generation in terms of lack of sufficient knowledge about degree transferstheir outcomes and particularly the low premium to tertiary degrees among some highly visible and disadvantaged groups raise important considerations about the existence of discrimination towards both immigrants and minorities (OECD, 2008, 2013). ${ }^{2}$ Even though with no clear pattern, migrant women remain in a particularly disadvantaged position in the labour markets discussed in this article with more articulated and complex outcomes to interpret, this highlighting the need to go deeper in the gendered pattern of migrants' and minorities' economic incorporation.

Finally, a word on limitations. The empirical assessment of immigrants' returns to education on their labour market outcomes (whatever the outcome considered) presents some significant difficulties, and this is especially true for studying the first generation. Data does not always allow us to distinguish where immigrants acquired their education (in the origin or in the destination country) and to encompass fully a complex phenomenon such as the transferability of educational degrees. Even when controlling for origin-country education, we may miss the effect of immigrants' self-selection into higher education based on the origin country, depending on the level of socio-economic development and the share of population obtaining tertiary education (Barro \& Lee, 2001). Moreover, data only rarely allow us to account for the effect of additional and country-specific human capital obtained in the receiving country under the form of training and/or work experience. The contributions in this thematic issue try to take account of these empirical problems where possible but more work needs to be done in this respect.

\section{Acknowledgments}

This research has been supported by funding from the European Commission (Grant number H2020 649255).

\section{Conflict of Interests}

The authors declare no conflict of interests.

\section{References}

Andrews, R. (2012). Labour migration, communities and perceptions of social cohesion in England. European Urban and Regional Studies, 22(1), 77-91.

Barro, R. J., \& Lee, J.-W. (2001). International data on educational attainment: Updates and implications. Oxford Economic Papers, 53(3), 541-563.

Brinbaum, Y. (2018). Incorporation of immigrants and second generations into the French labour market: Changes between generations and the role of human

\footnotetext{
${ }^{2}$ The field experiments in the GEMM project (Growth, Equal Opportunities Migration and Markets) will further contribute to this literature.
} 
capital and origins. Social Inclusion, 6(3), 104-118.

Cameron, D. (2011). PM's speech at the Munich Security conference. Gov.UK. Retrieved from www. number10.gov.uk/news/pms-speech-at-munich-se curity-conference

Chatterji, M., Mumford, K., \& Smith, P. N. (2011). The public-private sector gender wage differential in Britain: Evidence from matched employee-workplace data. Applied Economics, 43(26), 3819-3833.

Chiswick, B. R. (1978). The effect of Americanization on the earnings of foreign-born men. Journal of Political Economy, 86(5), 897-921.

Chiswick, B. R. (2000). Are immigrants favorably selfselected? An economic analysis. In C. D. Brettell \& J. F. Hollifield (Eds.), Migration theory: Talking across disciplines (pp. 61-76). New York, NY: Routledge.

Fellini, I., Guetto, R., \& Reyneri, E. (2018) Poor returns to origin-country education for non-Western immigrants in Italy: An analysis of occupational status on arrival and mobility. Social Inclusion, 6(3), 34-47.

Fernández-Reino, M., Radl, J., \& Ramos, M. (2018). Employment outcomes of ethnic minorities in Spain: Towards increasing economic incorporation among immigrants and the second generation? Social Inclusion, 6(3), 48-63.

Heath, A., \& Yu, S. (2005). Explaining ethnic minority disadvantage. In A. Heath, J. Ermisch, \& D. Gallie (Eds.), Understanding social change (pp. 187-224). Oxford: Oxford University Press.

Khoudja, Y. (2018). Employment and education-occupa- tion mismatches of immigrants and their children in the Netherlands: Comparisons with the native majority group. Social Inclusion, 6(3), 119-141.

Lancee, B., \& Bol, T. (2017). The transferability of skills and degrees. Why the place of education affects immigrant earnings. Social Forces, 96(2), 691-716.

Larsen, E. N., Rogne, A. F., \& Birkelund, G. E. (2018). Perfect for the job? Overqualification of immigrants and their descendants in the Norwegian labor market. Social Inclusion, 6(3), 78-103.

Lo lacono, S., \& Demireva, N. (2018). Returns to foreign and host country qualifications: Evidence from the US on the labour market placement of migrants and the second generation. Social Inclusion, 6(3), $142-152$.

OECD. (2008). OECD employment outlook 2008. Paris: OECD Publishing

OECD. (2013). International migration outlook 2013. Paris: OECD Publishing

OECD. (2014). International migration outlook 2014. Paris: OECD Publishing

OECD. (2017). International migration outlook 2016. Paris: OECD Publishing

Roksa, J. (2005). Double disadvantage or blessing in disguise? Understanding the relationship between college major and employment sector. Sociology of $E d$ ucation, 78(3), 207-232.

Zwysen, W., \& Demireva, N. (2018). An examination of ethnic hierarchies and returns to human capital in the UK. Social Inclusion, 6(3), 6-33.

\section{About the Authors}

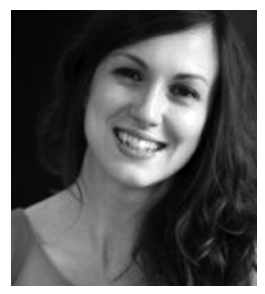

Neli Demireva (PhD) is a Senior Lecturer in Sociology at the University of Essex. Her research interests include migration, inter-ethnic ties, social cohesion, ethnic penalties and multiculturalism. She currently holds a BA grant on "Understanding the Ecology of Disadvantage: Betting Agents, Crime and the British Neighbourhood". From September 2015, she started working on the project "GEMM: Growth, Equal Opportunities, Migration and Markets" as part of the Horizon 2020 programme of the European Commission "EURO-2-2014: The European growth agenda Research and Innovation action 4: Migration, prosperity and growth". This project addresses the challenges and barriers that European countries face in managing the mobility of persons to realize competitiveness and growth.

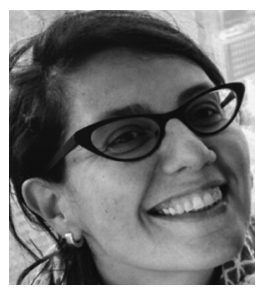

Ivana Fellini, PhD in Sociology and Social Research, is Assistant Professor in Economic Sociology and Sociology of Work at the University of Milano-Bicocca. Her research interests cover labour market trends, employment change and immigrants' incorporation in the labour market. She published several articles in national and international journals, among which Work, Employment \& Society, Migration Studies and International Migration Review. 